\title{
Growth and Structural Change: Trends, Patterns AND POLICY OPTIONS
}

\author{
Bart Verspagen \\ Paper prepared for the conference on 'Wachstums- und Innovationspolitik in \\ Deutschland und Europa. Probleme, Reformoptionen und Strategien zu Beginn \\ des 21. Jahrhunderts', Potsdam, 14 April 2000
}

First draft, April 2000

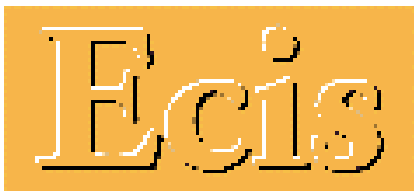

Eindhoven Center for Innovation Studies, Eindhoven University of Technology, PO Box 513, 5600 MB Eindhoven, the Netherlands.

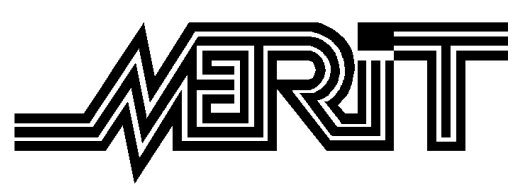

Maastricht Economic Research Institute on Innovation and Technology, Maastricht University, PO Box 616, 6200 MD Maastricht, the Netherlands. 


\section{Introduction}

On of the most researched topics in recent growth theory if the issue of convergence of productivity levels (e.g., Bernard and Jones, 1996, Benhabib and Spiegel, 1994, to name only a few of the many recent contributions). Mainstream economic theory (under which I will group both the old Solowian tradition, and the new growth models) traditionally attributes convergence to 'transitional dynamics', i.e., the fact that countries have not yet reached the steady state growth path that is predicted by these theories. Investment in capital goods is the main vehicle for convergence in this case, because countries with low capital-labour ratios will have high marginal returns to investment, and hence grow rapidly. In a different set of theories that are known as 'technology gap' theories (Fagerberg, 1994), convergence is caused by the international diffusion of technological knowledge. ${ }^{1}$

Convergence is not only a concept with theoretical importance, however. It obviously has important policy implications. Economic growth is often seen as solution to problems such as poverty or unemployment (it may admittedly hinder other policy goals, such as a clean environment). Hence achieving high growth is an issue that is high on the agenda of many policy makers. What is high growth, however, can only be judged by referring to other countries, i.e., looking at convergence or divergence of productivity or GDP per capita levels.

It has been observed that convergence in this sense was particularly strong during the postwar period in the OECD area (Verspagen, 1993). Earlier periods and/or larger country groups saw far less convergence than what was observed in the 1950s and 1960s in the OECD. In the 1970s or 1980s (depending on the precise country group), however, this rapid rate of convergence slowed down around the same time when overall growth rates of economies in the OECD began to slow down. What caused this slowdown in growth and convergence has occupied economic growth theorists ever since.

This paper will attempt to provide a different perspective on this issue. It will draw on a set of theories known as neo-Schumpeterian to try to provide an explanation of the slowdown in convergence. This theory puts structural change and technology at the forefront of the analysis. It investigates the hypothesis that there have been major technological breaks behind the observed convergence trends in the 1970s and 1980s. These technological breaks relate to the introduction of a number of related basic innovations, known jointly as Information and Communication Technologies (ICT). In the neoSchumpeterian perspective, such basic innovations are seen as a major source of renewed economic growth that goes hand-in-hand with major structural change ('creative destruction').

I will outline the neo-Schumpeterian perspective in the next section. This will also discuss a specific application by Perez and Soete (1988) of this framework to the issue of catching-up and convergence. The aim of the paper is to use this framework as an interpretation of the postwar convergence trends, and to speculate on the future trends of convergence. The main empirical trends on structural change during the period under investigation will be presented in Section 3. Section 4 presents a detailed account of convergence during the same period, and presents the accounting method that will be used

\footnotetext{
1 Some of the mainstream contributions now seem to have picked up this issue, e.g., Benhabib and Spiegel (1994).
} 
to carry out the empirical analysis in Section 5. Section 6 concludes and tries to draw some (policy) lessons for the future.

\section{Technology, Structural Change and Economic Growth: A Schumpeterian Perspective}

The theoretical starting point for the analysis in this paper is Schumpeter's theory about the economic impact of technological revolutions (Schumpeter, 1939, see also Freeman and Soete, 1997). This theory is essentially a historical account of capitalism since the Industrial Revolution. It states that major long-run fluctuations are caused by the clustering of so-called basic innovations during periods of depression. Basic innovations are major technological breakthroughs, such as the steam engine, the dynamo, the internal combustion engine, or, more recently, the digital computer, the transistor, or genetic engineering.

A major role in Schumpeter's theory is played by the entrepreneur (an especially visionary business man), who introduces the basic innovations in the economy, with the aim of making a profit (think of Boulton and Watt, George and Robert Stephenson, or, more recently, Bill Gates, as the prototype entrepreneurs). After its initial introduction, the basic innovations creates a bandwagon of imitations, each consisting of incrementally improved versions and enhancements of the basic design. It is through this bandwagon that the new technology diffuses through the economy, in a time period that may span decades. Because of the large opportunities for productivity and product quality improvement associated with the new technology, the economy grows at a rapid rate during this diffusion period.

In time, the technological opportunities for further improvement of the basic innovations wear off, and the boom period comes to an end. A recession, and eventually depression, sets in, and the economy slowly gets ready for the next wave of basic innovations. The succession of boom, recession and depression together forms a sequence of a long wave with 50-60 years periodicity. Schumpeter referred to the work of the Russian economist Kondratiev, who had identified such long waves (mostly in prices) in the 1920s, and after whom the phenomenon of long waves has been named afterwards.

There are many problems with Schumpeter's theory, one of the obvious ones being that he did not explain why basic innovations would cluster exactly during the depression periods of the long wave (Kuznets, 1940, was the first to bring out this point). A series of writings on the subject since the 1970s (e.g., Mensch, 1979, Kleinknecht, 1981, Freeman, Clark et al., 1982, van Duijn, 1983) has further developed and criticized this hypothesis. I will not be concerned with this specific debate here, but simply take the Schumpeterian argument about the impact of major technological breakthroughs without strictly adhering to the notion of a long wave (with strict periodicity) as such. I will 'extrapolate' (as many authors have done before me) the Schumpeterian argument by putting forward the hypothesis that modern Information and Communications Technologies (ICT) are a technological breakthrough that have / will le(a)d to a period of prolonged economic growth in the OECD area (e.g., Freeman and Soete, 1990, Freeman, 1994).

With this hypothesis, I will explore two issues. The first is the role of structural change in the process of economic growth driven by basic innovations. The second is the joint impact of structural change and technological change on the level of disparity of labour productivity during the different phases of the growth process (long wave). The rest of this section will explore these issues from a theoretical 
point of view, with the aim of formulating hypotheses about the medium-run tendencies for disparity of productivity levels in the largest OECD economies.

In Schumpeter's theory, the introduction of basic innovations leads to a process of 'creative destruction', in which sectors associated with the 'old' technologies decline, and new sectors emerge and grow. Freeman and Soete (1997) provide a historical overview of this process, discussing, among other things, the role of 'leading sectors'. Creative destruction, of course, is nothing else than a more prosaic term for 'structural change', i.e., changes measured ultimately by variations in the shares of 'sectors' in output or employment.

The overview in Freeman and Soete (1997) shows how technological change and creative destruction since the First Industrial Revolution has mainly been taking place within the manufacturing sector, with transportation as the only services branch that was affected in a major way. Starting with textiles and clothing, the roughly two centuries since then have brought us new branches such as iron and steel making, chemicals, motor vehicles, machine tools and electronics. This has led authors such as Kaldor (1970) and Cornwall (1977) to formulate the hypothesis that the manufacturing sector bears special importance for economic growth in a broader sense.

In Kaldor (1966), the expansion of the manufacturing sector is seen as the driving force for economic growth. This expansion is essentially demand-driven, and is made possible by a shift of labour from agriculture (where hidden unemployment is present) to manufacturing. Kaldor (1970) further develops the factors behind strong growth in manufacturing. Here, he stresses the joint forces of demand increases leading to increased productivity (via Verdoorn's law), in turn leading to increased demand, thus setting in motion a process of 'cumulative causation'. Dixon and Thirlwall (1975) have formalized this argument in a regional setting.

The role of productivity increase in the manufacturing sector for macroeconomic growth is further stressed by Cornwall (1976) and Cornwall (1977). Cornwall develops Kaldor's idea of manufacturing as a leading sector by explicitly referring to technological change in selected manufacturing sectors as a driving force for productivity improvement in a whole range of sectors, through technological interdependence as well as input-output linkages between sectors. In this Kaldor-Cornwall perspective, manufacturing is thus seen as the prime sector leading to economic growth.

The technological revolution underlying the present upswing in economic growth, broadly characterized as 'Information and Communication Technologies' (ICT), is one that, although it was originally based in manufacturing (microelectronics), is now primarily associated with the rise of services sectors such as business services (as an ICT using sector) and software development (as the main ICT generating sector) (Castells, 1996, Petit and Soete, 2000) This phenomenon may be interpreted as the result of supply factors (the nature of basic innovations in ICT), as well as demand factors. On the supply side, 'information' as the basic ingredient into ICT is by its nature an intangible good, and this naturally leads to a large importance of intangibles (services) alongside hardware (manufactured) in the changes associated with ICT.

On the demand side, the argument basically builds on Pasinetti's (1981) interpretation of economic growth. His theory stresses the role of demand in structural change. The basis for Pasinetti's argument is the Engel curve, which says that demand for any good eventually saturates at high levels of income. 
In Pasinetti (1981), the emphasis is on the implications of this saturation for structural unemployment, but in his (1993) contribution, the implications for economic growth are analyzed more deeply as well. Saturation of demand for a good (declining income elasticities) leads to a slowdown of economic growth, just as the wearing-off of technological opportunities leads to a slowdown in Schumpeter's original theory.

The interpretation is then that the demand for manufactured goods has reached a phase of declining income elasticity, thus leading to slower growth for countries specialized in the manufacturing sector, and providing opportunities for growth based on ICT (which, as was argued, has an important services content). Such an argument supports the notion that ICT-based growth only takes off in full potential after developments on the service part of ICT (e.g., the internet) have gained crucial momentum.

Following this line of argument, Fagerberg and Verspagen (1999), put forward and tested the hypothesis that the Kaldor-Cornwall perspective on the importance of manufacturing was very specific to the time frame in which it was formulated (the 1960s and early 1970s). This period was, in the neoSchumpeterian interpretation of Freeman and Soete (1997), the heyday of mass-production based innovation systems. This mode of production, initiated by basic innovations such as the assembly line, the motor car and plastics in the United States in the first half of the $20^{\text {th }}$ century, is seen by these neoSchumpeterian authors (e.g., Freeman and Soete, 1997) as the last 'long wave' based firmly in manufacturing.

Fagerberg and Verspagen (1999) indeed found that the correlation between growth in manufacturing and overall growth was much weaker in the 1980s and 1990s than before, at least for the sample of developed (OECD) countries. In the (SouthEast Asian) NICs, manufacturing still plays a strong role, leading to the hypothesis that the manufacturing base of ICT has shifted to these countries. This is indeed a popular view (see also Castells, 1996) that corroborates with impressions one gets from trade statistics.

What does this changing role of manufacturing in the light of technological revolutions and their impact on growth imply for comparative growth between the most advanced nations in OECD and Europe? I will attempt to tackle this issue by referring to the notion of technological catching-up. This theory is based on the ideas first raised by Gerschenkron (1962), and later formalized by Gomulka (1971). The hypothesis is that countries that are initially 'backward' in a technological sense have a large potential to imitate knowledge from the more advanced countries. Because imitation is generally cheaper (but not costless) than innovation, this provides these 'backward' countries with a potential for high growth. One may say that this theory puts Schumpeter's idea of bandwagons into an international perspective.

Whether or not the potential for such catching-up based economic growth is realized depends on how well a country is able to assimilate knowledge from abroad. Such assimilation obviously requires skills that depend, among other things, on human capital, the quality of the infrastructure, and institutions such as politics and banking. Abramovitz (1979) has used the term 'social capability' to refer to the set of factors that support assimilation of knowledge from abroad.

The importance that Abramovitz and others (Fagerberg, 1994) attach to social capability neatly lines up with the importance that authors such as Freeman (1986) and Perez (1983) attach to institutions in a 
neo-Schumpeterian innovation of basic innovations and the long wave. These authors argue that each new set of basic innovations that form the starting point of the long wave create new institutional requirements. Most obviously, this relates to educational demand related to the new skills that technology requires, but one may also think of other factors. One example is the introduction of standardized time as a result of railroads, or the role of venture capital, universities and 'culture' in supporting major technological breakthroughs in ICT in Silicon Valley Saxenian (1994).

Combining the role of institutional factors in both the emergence of new growth related to basic innovations, and catching-up based growth, Perez and Soete (1988) argue that catching-up based growth is easier in some phases of the long wave than in others. Their main theoretical concept is the technology life cycle, which distinguishes four phases: introduction, early growth, late growth and maturity. Perez and Soete argue that entry of countries in technological systems is easiest in either the introduction phase, or the maturity phase. My interest here is mainly in entry during the introduction phase, so I will leave entry during the maturity phase unexplained.

In the introduction phase, there is little specific knowledge that is available or necessary for the new technological system. General (university) knowledge brings a country a long way to enter the new field. Given that a country has a reasonably well-developed system of public knowledge generation, entry is thus relatively easy during the introduction phase of a new basic innovation. Entry becomes much more difficult in the growth phases, because then the technological system will have evolved into a state where tacit knowledge related to experience and learning-by-doing plays a much more important role. Thus, one would expect that the foundations for catching-up based growth would be laid during the introduction phase of a new set of technologies, after which the 'window of opportunity' closes again for a long period.

As will be argued below, the current situation in the world economy may be viewed as the introduction phase of a new set of basic innovations, and hence 'a window of opportunity' for further convergence to set in. Thus, I will try to apply the arguments by Perez and Soete to the current situation with regard to disparity of productivity levels, and try to draw conclusions on convergence in the medium-run future.

However, Perez and Soete talk about opportunities, and they recognize that opportunities are not always taken. Thus, although the potential for catching-up may be high during the introduction of a new technological system, one may also see that these opportunities are not taken. The 'old leader' may be the country that implements the new technology earliest, and then further divergence may the result rather than convergence.

What I will do in the remainder of this paper is interpret the recent history of convergence in the most advanced OECD countries in light of the two points made above. Summarizing, these two points are:

1. That structural change is a major part of technological revolutions and the economic growth they bring, and that the most recent technological revolution (ICT) has brought a declining role of the manufacturing sector in the most advanced OECD countries.

2. That the rate of convergence of labour productivity (or catching-up based growth) is likely to differ between periods, and that the ICT revolution may bring with it both divergence or convergence, 
depending on how well other economies than the United States (the 'old leader') are able to adapt to the technological breakthroughs.

\section{Structural Change and Growth: Empirical Trends}

This section will apply a database developed by researchers at the Groningen Growth and Development Centre ${ }^{2}$ (GGDC) (see, e.g., Ark, 1996) to the issue of structural change and economic growth. The data used consist of value added data in constant prices and employment for six countries: Germany, France, Italy, United Kingdom, United States and Japan. Ten sectors are present in the database, which will be introduced below. The GGDC database does not provide sectoral Purchasing Power Parities or similar variables that can be used to compare productivity and output levels internationally. I will therefore use OECD Purchasing Power Parities for the economy as a whole to convert national currencies to US PPP \$. Where the constant prices in the GGDC database do not refer to 1990 (which is the base year for most countries), I use the US GDP price index to convert to 1990 PPP \$. Obviously, this approach introduces errors, but until a consistent dataset with sectoral PPPs is available, it is the best one can achieve.

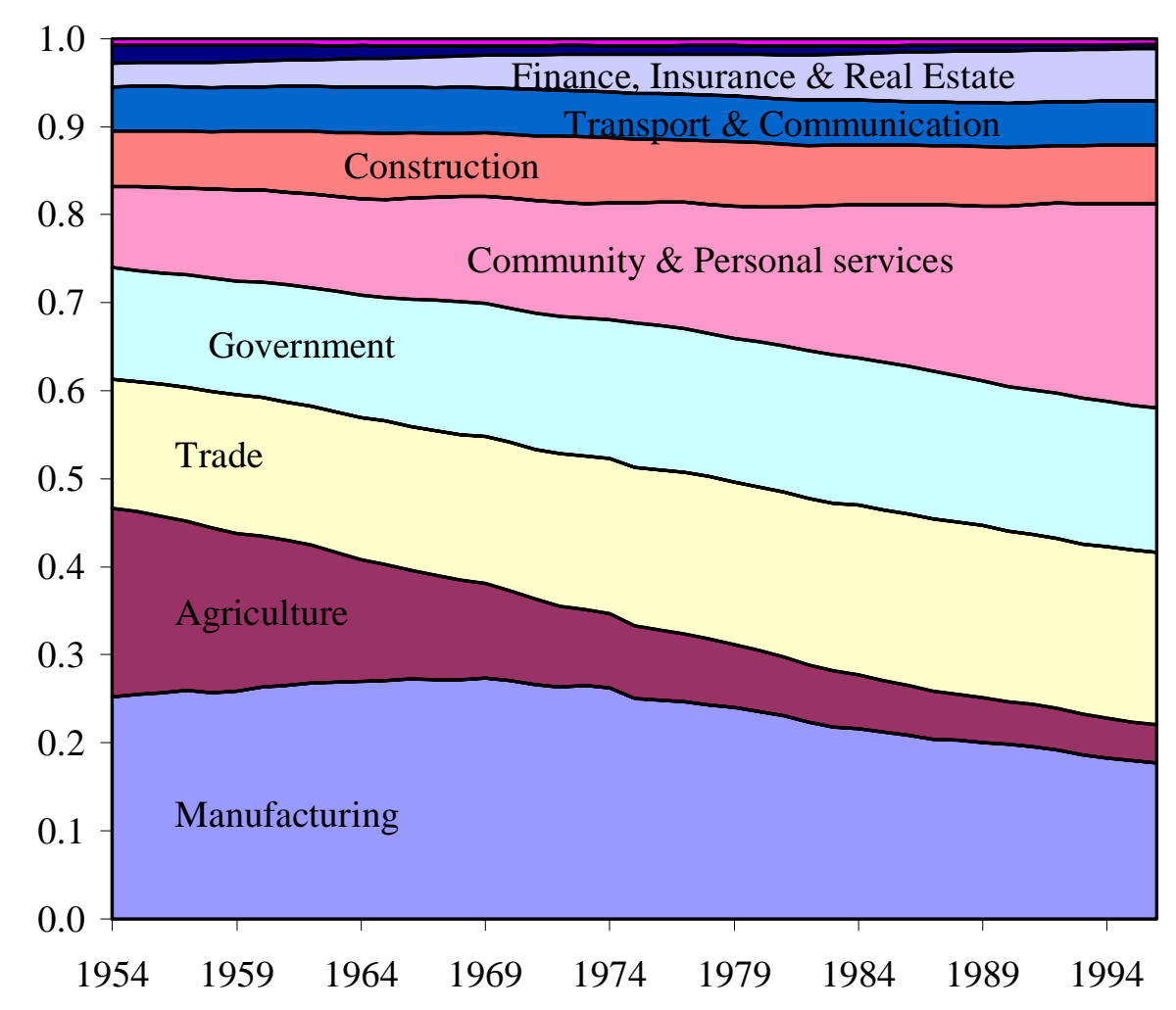

Figure 1. Employment shares in the 6 countries, 1954-1996

Figure 1 shows the share of labour resources devoted to each of the 10 sectors in the database. The shares are weighted averages of the 6 countries. There are two primary sectors in the database: argiculture and mining. The manufacturing sector is considered as a total. The other sectors are construction; public utilities; wholesale and retail trade (trade); finance, insurance, real estate and

\footnotetext{
${ }^{2}$ GGDC Sectoral Database, University of Groningen (Fourth Quarter 1999) (unpublished).
} 
other business services; community and personal services; transport and communication, and government services.

In the 1950s, the manufacturing sector was the largest of these 10 sectors, with approximately one quarter of total labour allocated to this sector (sectors are ranked according to their employment size in 1954, larger sectors are lower in the figure). The two small sectors at the top of the figure are mining (lowest) and public utilities (highest). Table 1 gives more precise details about the relative decline and stagnation of the 10 sectors.

Table 1. Sectoral dynamics (employment share and labour productivity growth), 6 countries average, 1965-1996

\begin{tabular}{llllc}
\hline & Share 1954 & Share & 1996 & \% increase share \% Y growth \\
\hline Manufacturing & 0.25 & 0.18 & -30.0 & 3.3 \\
Agriculture & 0.21 & 0.04 & -79.7 & 4.3 \\
Trade & 0.15 & 0.20 & 34.8 & 2.2 \\
Government & 0.13 & 0.16 & 28.6 & 0.4 \\
Community \& Personal services & 0.09 & 0.23 & 151.2 & 0.9 \\
Construction & 0.06 & 0.07 & 6.9 & 0.9 \\
Transport \& Communication & 0.05 & 0.05 & -0.3 & 3.1 \\
Finance, Insurance and Real Estate & 0.03 & 0.06 & 121.6 & 1.3 \\
Mining & 0.02 & 0.00 & -76.9 & 3.7 \\
Utilities & 0.01 & 0.01 & -16.8 & 3.9 \\
\hline
\end{tabular}

Until 1970, manufacturing slightly increases its share, but from then on, the sector declines in terms of relative employment. The share of agriculture falls sharply during the whole period. Together with mining, this is the sector that shows the largest percentual decrease of the labour share. Transport and communication (slightly) and utilities (and manufacturing) are the other sectors that see their share in employment decline. The sectors with the strongest increase in employment are two services sectors: community and personal services, which grows from an already fairly large base in 1954, and finance, insurance and real estate, which is a much smaller sector (see also Petit and Soete, 2000).

Table 1 also gives the average annual compound growth rate of labour productivity in the sectors (6 countries weighted average). Throughout the paper, labour productivity is defined as value added in 1990 PPP \$ per worker (per working hour would be a better indicators, but working hours are only available for a subset of the six countries). The results for labour productivity growth generally show a tendency for productivity growth to be highest in sectors that produce tangible goods. Agriculture shows the highest growth rate, followed by the two energy related sectors (utilities, mining) and manufacturing. The services sectors all show significantly lower productivity growth rates, especially so government, community and personal services and finance, insurance and real estate. 


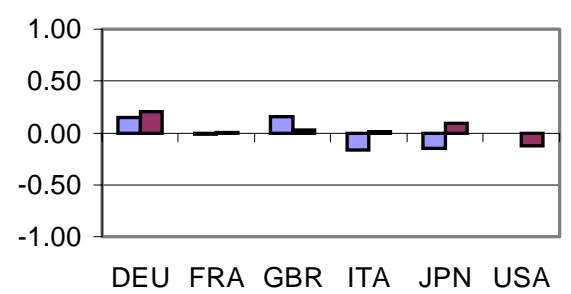

Trade

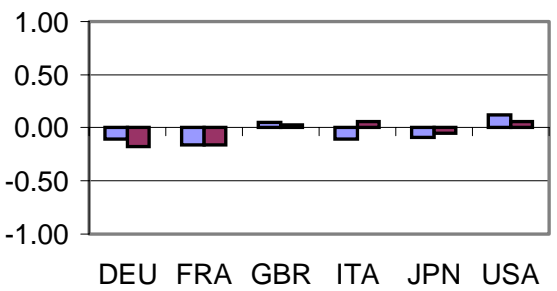

Community \& Personal services

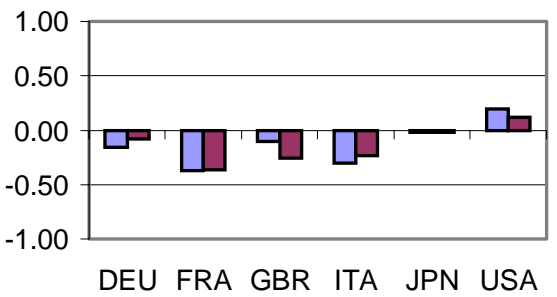

Transport \& Communication

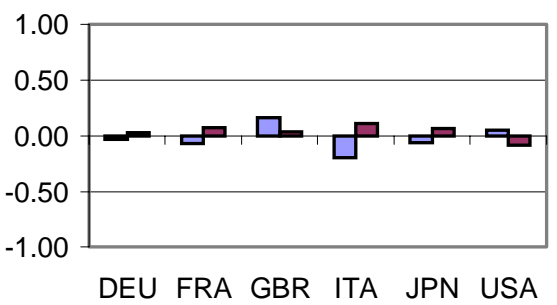

Mining

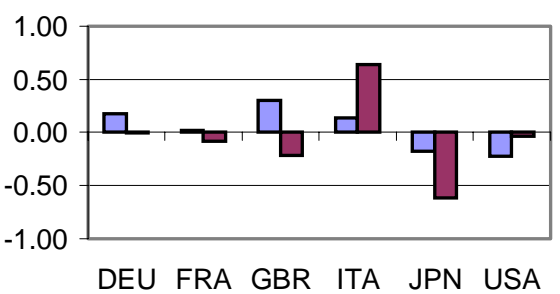

$\square 1954$

$\square 1996$

口1954

ㅁ1996

\begin{tabular}{|l|}
\hline$\square 1954$ \\
$\square 1996$ \\
\hline
\end{tabular}

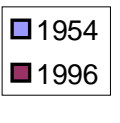

$\square 1954$

$\square 1996$

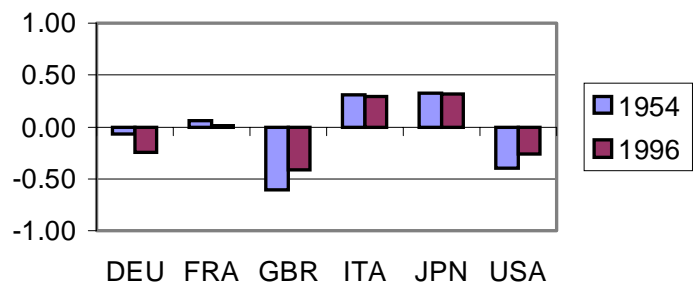

Government

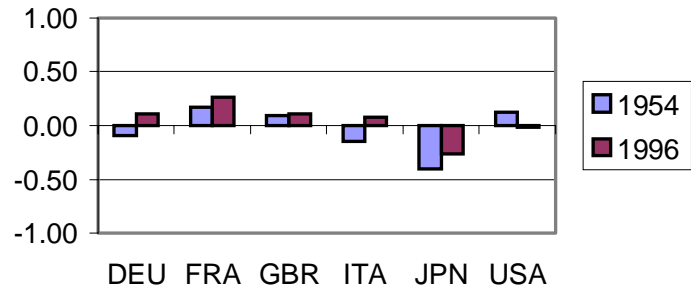

Construction

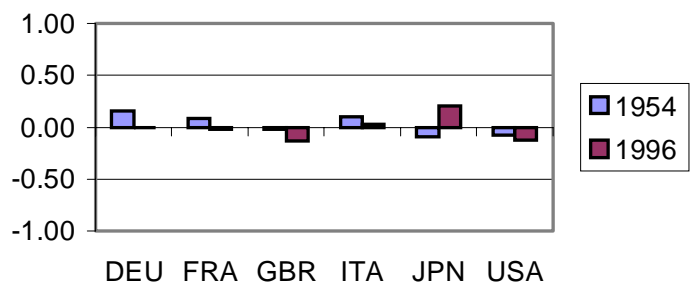

Finance, Insurance \& Real Estate

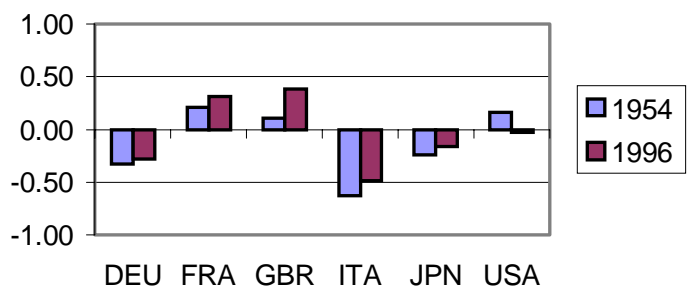

Utilities

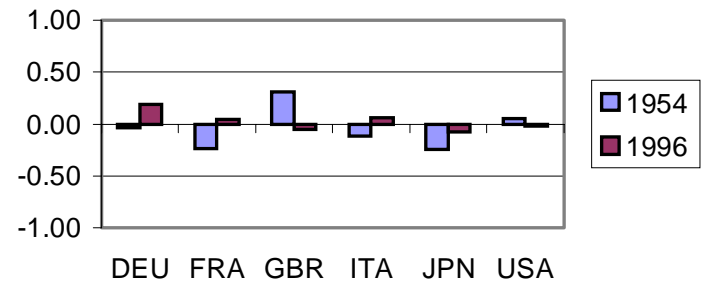

Figure 2. Specialization patterns 
Taking these productivity growth rate at face value, and combining them with the increased labour share of these sectors suggest the relevance of the analysis by Baumol (1967). This paper, that gave rise to the term 'Baumol's disease argues that a demand pattern that favours sectors with low productivity growth will eventually drive the economy to a state of low productivity growth. Keeping in mind the so-called productivity slowdown that hit the OECD countries during the 1970s, this seems as a convincing explanation of events.

However, it is obvious that the services sectors with slow productivity growth in Table 1 are also the sectors that have large difficulties in measuring output (Ark, Monnikhof et al., 1999). This raises the suspicion that the slow rates of productivity growth are seriously affected by measurement error. Certainly, anecdotal impressions one gets from, for example, the finance sector, would suggest that technological change and productivity growth play a much more important role that suggested by Table 1.

However, Baumol's disease nor the issue of measurement of productivity and output in services are the main topic of this paper. As explained in the introduction, the analysis here will instead look at the role of specific sectors in the process of convergence of labour productivity. In case the conclusions would suggest that the above mentioned services industries are important for this process, this might well be related to an important extent to measurement issues.

To what extent do production structures really differ between the countries in our sample? Figure 2 gives an answer to this question. The figure displays so-called revealed comparative advantage indices for each of the sectors. This index is constructed by first calculating the share of each country in a sector's total employment (across the 6 countries). This share is divided by the share of the country in overall employment. Because the resulting indicator is not symmetric around its natural (weighted) mean, i.e., one, a correction is applied. The actual indicator used is calculated as $(\mathrm{X}-1) /(\mathrm{X}+1)$, where $\mathrm{X}$ is the ratio of the sectoral share and the overall share. This indicator lies between -1 and 1 . A zero value corresponds to a neutral value, positive (negative) values point to (de)specialization in the sector.

Figure 2 gives the indicators for the years 1954 and 1996. While some of the specialization patterns observed in 1954 persist in the period until 1996, there are also important reversals. In manufacturing, for example, such a reversal takes place in the UK (declining values of the indicator) and Japan (increasing values). Germany shows positive specialization in manufacturing over the whole period. It must be noted, however, that the values for all countries are rather close to zero, which indicates that the shares of manufacturing in labour do not differ too much between countries.

Agriculture shows a much more pronounced specialization pattern, with Italy and Japan as the two countries specialized in this sector. The United Kingdom, the United States and, in 1996, Germany show strongly negative values. Mining is a sector that shows both strong specialization, and strong changes in the specialization pattern over time. This is caused by important role of energy resources in this sector.

In the services sector, trade and transport and communication show relatively even specialization patterns. Community and personal services, and finance, insurance and real estate show larger 
differences between countries. In the latter two sectors, the signs of the specialization patterns are relatively stable.

How important are these differences for productivity growth? This question obviously has many theoretical dimensions. A preliminary answer can be provided by a simple calculation, which is displayed in Table 2. The table displays a matrix, with countries in the rows and columns. The growth rates in the cells (percentages) were calculated as follows.

First, the level of labour productivity in each sector in each country was calculated for 1954 and 1996. Denote this by $y_{i j}$, with the subscripts $i$ and $j$ denoting a country and sector, respectively. From this, the annual average growth rate of labour productivity was calculated. This growth rate is indicated by a hat above the variable. Then the share of each sector in total labour in a country was calculated $\left(\sigma_{i j}\right)$. By definition, we have $y_{i}=\sum_{j} y_{i j} \sigma_{i j}$. Now define the alternative macroeconomic productivity level $y_{i k}^{*}=\sum_{j} y_{i j} \sigma_{k j}$, which is the hypothetical level of productivity using one country's $(k)$ structure, and another country's $(i)$ productivity levels. This hypothetical level of productivity can be constructed for 1954 and 1996, and the growth rate of this variable can be constructed. The value in row $k$, column $i$ of Table 2 is equal to $\hat{y}_{i}-\hat{y}_{i k}^{*}$. A positive number thus means that the country in the column would 'benefit' (in terms of productivity growth) from adopting the structure of the country in the row.

Table 2. The impact of structure on growth

\begin{tabular}{llllllll}
\hline \multicolumn{9}{c}{ Growth } & & & & \\
\hline \multirow{5}{*}{ Structure } & DEU & FRA & GBR & ITA & JPN & USA \\
& & 0.2 & 1.3 & -0.1 & -1.0 & 1.4 \\
& FRA & 0.1 & & 1.1 & 0.0 & -1.0 & 1.4 \\
& GBR & -0.8 & -1.0 & & -0.3 & -2.0 & 0.5 \\
ITA & 0.1 & -0.1 & 1.3 & & -1.1 & 1.0 \\
JPN & 1.1 & 1.0 & 2.5 & 0.8 & & 2.3 \\
USA & -1.7 & -1.6 & -0.5 & -1.8 & -2.8 & \\
\hline
\end{tabular}

Japan is the country that has the production structure that is most favourable to high productivity growth. This is indicated by the fact that all values in the column for Japan are negative. In other words, adopting any other production structure than its own would have a negative impact on productivity growth in this country. The United States are the country with the 'worst' production structure, as indicated by all positive values in the column for this country. In Europe, the United Kingdom has a relatively 'bad' structure, while France, Germany and Italy show mixed results.

The finding that the United States and the United Kingdom have 'bad' economic structure is, of course, related to their strong specialization in services, as shown in Figure 2. One has to keep in mind, however, the warning issued above about the measurement of productivity growth in services, which means that the results in Table 2 might be biased against these two countries. 


\section{Convergence of labour productivity levels}

The post world war II period has been one of strong convergence of productivity levels in the OECD area (Maddison, 1995). During the most recent period, however, this process of convergence seems to have slowed down considerably, however. For the 6 countries in our sample, this is illustrated in Figure 3. The figure gives the coefficient of variation (standard deviation divided by the unweighted mean) of labour productivity levels. A falling coefficient of variation points to convergence.

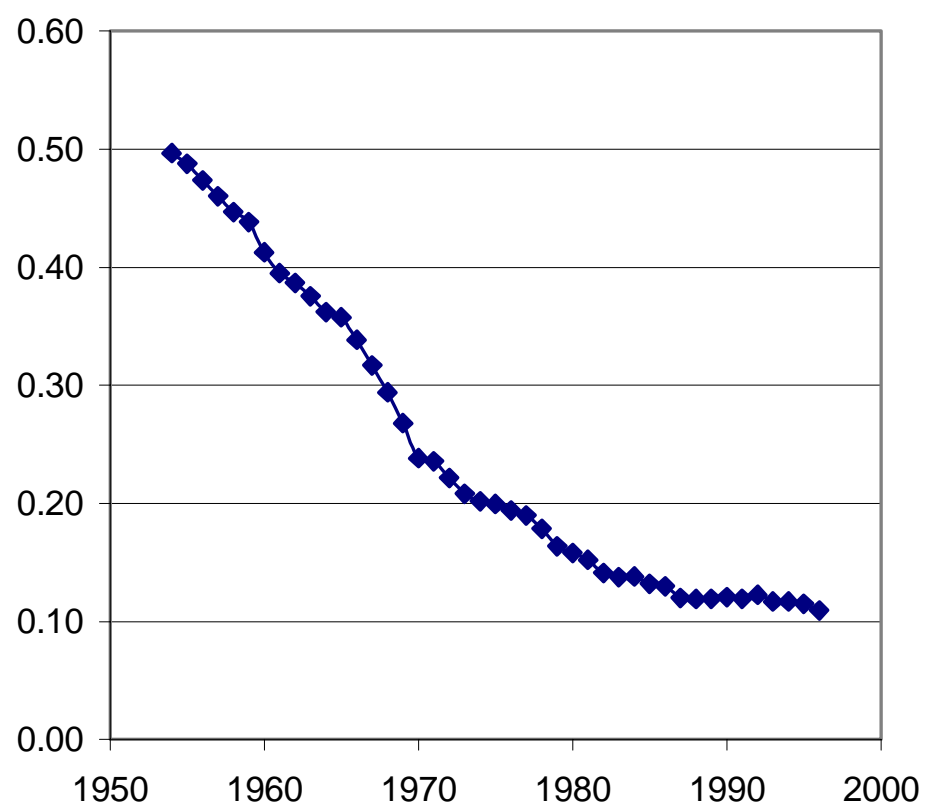

Figure 3. Coefficient of variation of labour productivity in the 6 countries

The figure indeed shows a strongly falling value of the coefficient of variation, at least until the mid1980s. Until 1970, the indicator seems to fall almost linearly at a rather high (absolute) slope. The period 1970 to mid-1980s also shows a linear decrease, but seemingly at a somewhat smaller (absolute) slope. From the mid 1980s onwards, however, there is little or no change in the coefficient of variation.

What causes this fall in the speed of convergence? The present analysis will attempt to answer this question from the point of view of economic structure. Thus, a useful starting point is to look at convergence trends at the sectoral level, by calculating the coefficient of variation of the levels of labour productivities at the sectoral level. This is what is displayed in Figure 4.

The figure shows that (strong) convergence is far from a general phenomenon at the sectoral level. Substantial convergence over a long period is observed in construction, manufacturing, utilities, trade and agriculture. Transport and communication shows convergence over a limited period in the 1960s, but not much before or after that. The government sector, which starts from a very low level of disparity in the 1950s, only shows convergence until around 1960. Finance, insurance and real estate 
shows convergence during a limited period in the 1970s, similarly (but much stronger) for mining. Community and personal services shows virtually no convergence at all.
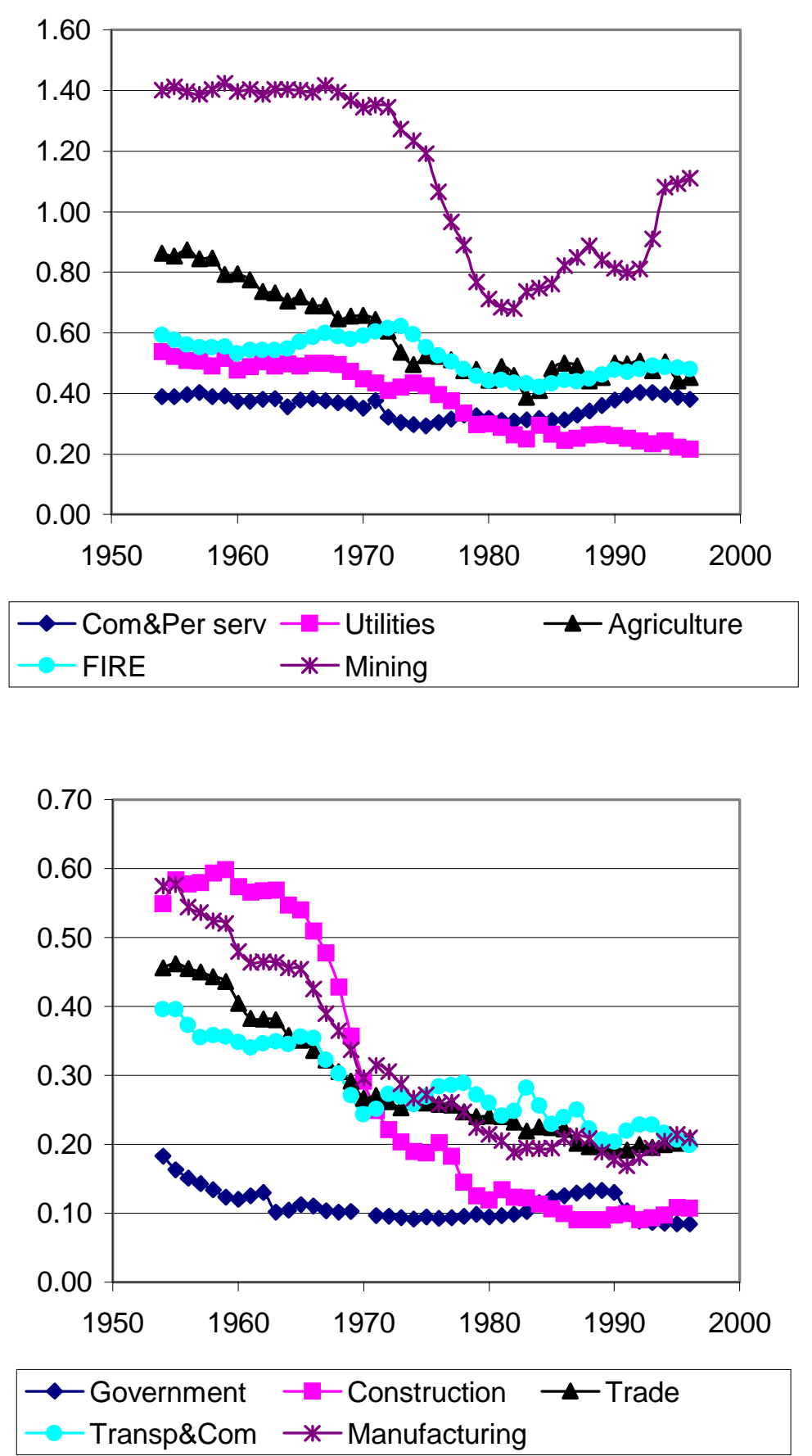

Figure 4. Coefficient of variation of labour productivities among the 6 countries, sectors

Obviously, the sectoral trends all contribute in some form to the aggregate picture in Figure 3. However, it is not immediately obvious from Figure 4 which sectors are mainly responsible for the slowdown in convergence since the mid-1980s. In order to answer this question more precisely, a method will be developed that decomposes the changes of the coefficient of variation over time into a 
contribution of the separate sectors. The method starts from the definition of the coefficient of variation (denoted by $c$ ):

$c=\frac{s}{m}, m=\frac{1}{n} \sum_{i} y_{i}, s^{2}=\frac{1}{n} \sum_{i}\left(y_{i}-m\right)^{2}$,

where the subscript $i$ indicates as before a country, and $n$ is the number of countries (6). Differentiating $c$ with respect to time gives (I use dots above variables to indicate a time derivative) $\dot{c}=\frac{\dot{s} m-\dot{m} s}{m^{2}}$. In order to 'translate' to changes in productivity levels at the country level, one also needs the following partial derivatives: $\frac{\partial s}{\partial y_{i}}=\frac{y_{i}-m}{n s}, \frac{\partial m}{\partial y_{i}}=\frac{1}{n}$. Substituting these into the expression for $\dot{c}$ gives

$\dot{c}=\sum_{i} \frac{\dot{y}_{i}}{y_{i}} \frac{y_{i}}{m n}\left(\frac{y_{i}-m}{s}-c\right)$

The first fraction under the summation sign is the proportionate growth rate of labour productivity in a country. The second fraction is the country's productivity level divided by the sum of productivity levels in all countries. The terms between brackets give the deviation of the country's productivity level relative to the mean, scaled by the standard deviation and the coefficient of variation. Hence, the change of the coefficient of variation if a weighted sum of the productivity growth rates of the individual countries. The sign of the weights depends on the magnitude of the country's deviation from the mean productivity levels. Countries below the mean productivity level always have a negative weight (i.e., the more rapid they grow, the more rapid the coefficient of variation will fall). Countries with very high productivity levels have a positive weight, hence rapid growth in these countries increases disparity. ${ }^{3}$

The final step is to decompose the country growth rates of productivity. By definition, $y=\sum_{j} \sigma_{j} y_{j}$, hence aggregate productivity may change as a result of changes in the sectoral allocation of labour $(\sigma)$ or sectoral productivity growth $(y)$. Differentiating, one arrives at $\dot{y}=\sum_{j}\left(\dot{\sigma}_{j} y_{j}+\sigma_{j} \dot{y}_{j}\right) \Rightarrow \frac{\dot{y}}{y}=\sum_{j} \frac{q_{j}}{q}\left(\frac{\dot{\sigma}_{j}}{\sigma_{j}}+\frac{\dot{y}_{j}}{y_{j}}\right)$, where $q$ is production volume.

Substituting this into the above expression gives:

$\dot{c}=\sum_{i} \frac{y_{i}}{m n}\left(\frac{y_{i}-m}{s}-c\right) \sum_{j} \frac{q_{j}}{q} \frac{\dot{y}_{j}}{y_{j}}+\sum_{i} \frac{y_{i}}{m n}\left(\frac{y_{i}-m}{s}-c\right) \sum_{j} \frac{q_{j}}{q} \frac{\dot{\sigma}_{j}}{\sigma_{j}}$.

The first term on the right hand side is the effect related to (sectoral) productivity growth, which I will label as 'technological progress'. The second term is related to changes in the allocation of labour to sectors, which I will label 'structural change'. Within each of these terms, one can simply group all terms for a sector $j$, and sum them to obtain the change of the coefficient of variation that can be associated with both technological progress and structural change in that sector. This can be formalized as follows:

\footnotetext{
${ }^{3}$ Obviously, it is easy to derive formally the border line between negative and positive weights: $\tilde{y}_{i}=c s+m$.
} 


$$
\dot{c}_{j}^{T P}=\sum_{i} F_{i} \frac{q_{j}}{q} \frac{\dot{y}_{j}}{y_{j}}, \dot{c}_{j}^{S C}=\sum_{i} F_{i} \frac{q_{j}}{q} \frac{\dot{\sigma}_{j}}{\sigma_{j}} \text {, with } F_{i}=\frac{y_{i}}{m n}\left(\frac{y_{i}-m}{s}-c\right)
$$

In this formula, the superscript $T P$ denotes 'technological progress', the superscript $S C$ denotes structural change.

The derivation of the decomposition has been done in continuous time. Applying this to discrete data would require a number of interaction terms, and this makes the formula quite complicated. One may expect that the impact of these interaction terms (in general, changes multiplied by changes) is relatively small as compared to the non-interaction terms. Whether this is true or not can be assessed by approximating the real change of the coefficient of variation by the above formula (applied to discrete data), and calculating the difference between the real change and the approximation. This is what was done, and in all cases the approximation was very close to the real value. Therefore, the analysis here will not bother any further with the interaction terms, and present the results of the calculations of the above formula applied to discrete data.

\section{Empirical results and interpretation}

One possibility for the slowdown in convergence would be that the macroeconomic scope for convergence has become low as a result of convergence itself. In this case, the macroeconomic differences in productivity levels would be so small that further convergence was difficult to achieve. In terms of the decomposition method above, this would be reflected in the country-weights $F$. Figure 5 presents the values of these weights over time.

The figure shows a remarkable pattern, evolving from an almost complete bipolar distribution to a much more even one. In the 1950s, the United States has a high positive value of the weight, and all other countries a negative value. All these five countries with negative weights are grouped in a small range along the vertical axis. This means that, under the normal circumstance of positive macroeconomic productivity growth, the United States alone are 'responsible' for any upward pressure on the coefficient of variation during this period.

This situation changes slowly. The United States weight declines, and that for France, Italy and Germany increases. At the end of the period, these are the four countries with positive weights. The weights for Japan and the United Kingdom also decline over time, and these two countries become the only ones with negative weights at the end of the period.

The figure does not give any indication of what this implies for convergence. Undocumented calculations (available on request) show that the net impact of the changes in Figure 5 is very small. This was shown in an experiment in which the weights in the decomposition were fixed hypothetically at their 1960 value. In this case, the trend in the coefficient of variation was very similar to the one actually observed. In 1996, the hypothetical coefficient of variation that results from the calculations is 0.10 , instead of the actually observed value of 0.11 . The only period during which the difference between 1960 and actual weights is somewhat visible is the recession period 1989 - 1992, which mostly affects the United Kingdom and Japan in Figure 5. 


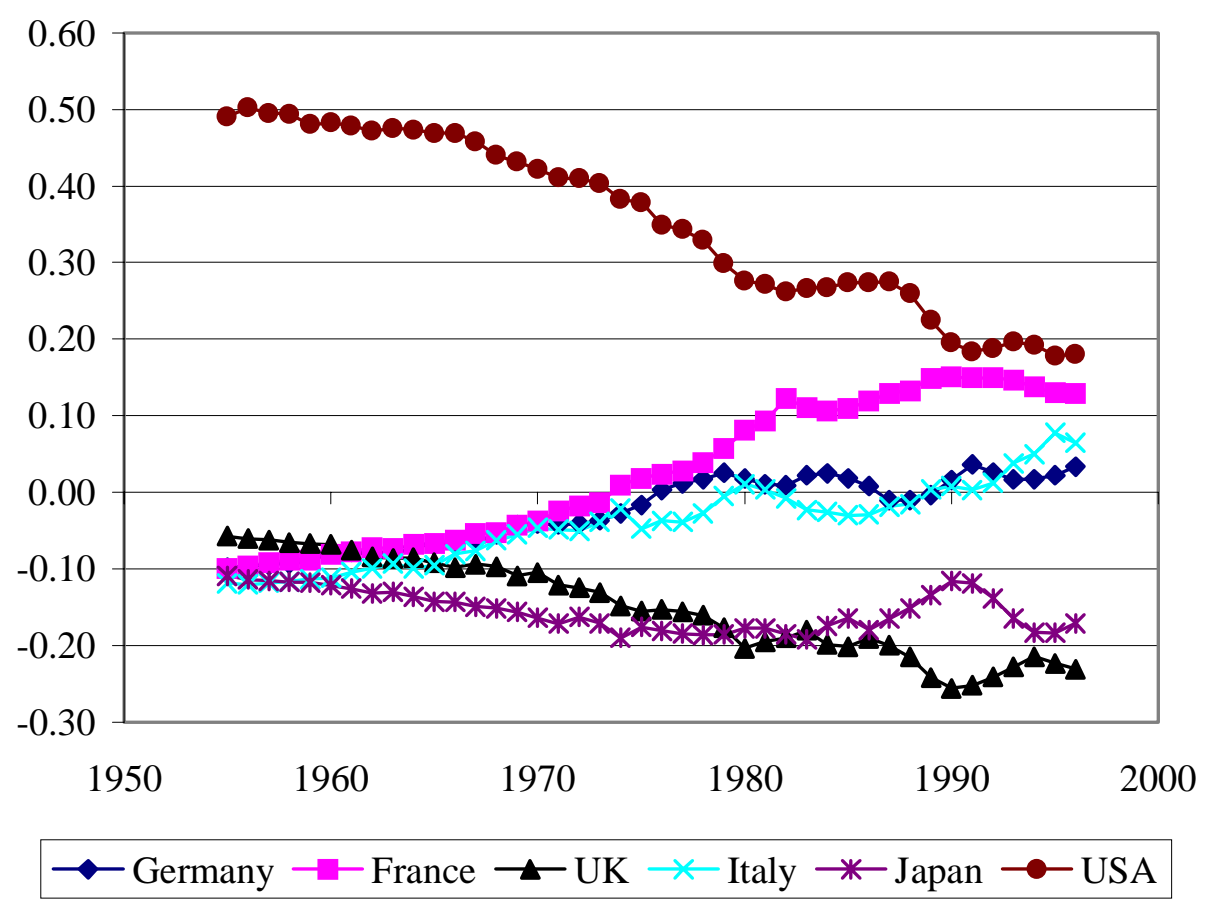

Figure 5. Country weights in the convergence decomposition

This result essentially shows that there is no convincing overall macroeconomic explanation behind the convergence slowdown of the mid-1980s. The analysis will therefore turn to the sectoral level, using the decomposition technique introduced above. The technique gives calculations on the annual change of the coefficient of variation. In order to rule out short-run fluctuations, the initial (annual) results were averaged over five year period, with the exception of the start and end of the overall period, where shorter time intervals were used. Figure 6 shows the overall results, summed over all 10 sectors, but split up by the categories 'structural change' and 'technological progress'.

The convergence slowdown is evident from the fact that the absolute value of the average yearly decline of the coefficient of variation falls since the early 1970s. During 1985-1994, the change becomes almost zero. Note that the last period in the graph overlaps with the previous period. During this most recent period, the tendency for the coefficient of variation is to decline again (as is also evident in Figure 3).

Between the two categories 'structural change' and 'technological progress', the latter has the largest influence, except during the period 1956-1964, when the absolute value of the two factors is comparable. ${ }^{4}$ However, the absolute value of both categories declines over time, so that one may say that both factors contribute to the slowdown of convergence. For the most recent period, structural change even has a net diverging influence, as is shown by the positive values for this factor over the 1990s.

\footnotetext{
${ }^{4}$ It must be noted, however, that the short period (a year) over which the basic calculations were made, tends to hold down the value of the structural change component. Yearly changes in employment shares are small as compared to yearly productivity growth rates. A similar effect, but in a different context, is found by Timmer and Szirmai (2000) and Fagerberg (2000).
} 


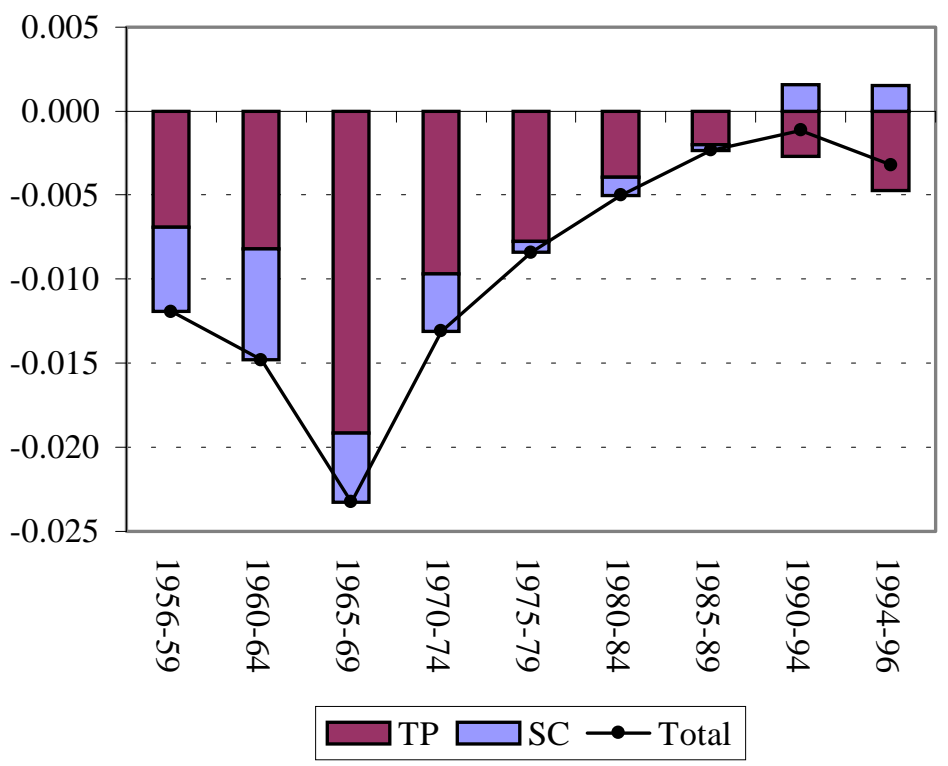

Figure 6. The contribution of structural change and technological progress to the slowdown of convergence

Figure 7 presents the sectoral decomposition of the trends in Figure 6. Several conclusions emerge from these graphs. First, with the exception of the small sectors mining and utilities, as well as community and personal services, each of the sectors broadly shows a pattern in which the absolute value of the contribution to the convergence slow down becomes smaller over time, especially in the 1970s. The most likely factor behind this general tendency is the overall slowdown of the rate of technological progress that may be associated with the slow maturing of the dominant technological system during this period.

Second, the manufacturing sector was by far the largest factor behind the strong convergence of the 1960s and 1950s. The sudden decline of the manufacturing impulse for a falling coefficient of variation is also a large factor behind the slowdown of convergence in the 1970s and beyond. This result is in general accordance with the Kaldor-Cornwall idea of the manufacturing sector as a driving force of economic growth during the period until the 1970s, and the findings by Fagerberg and Verspagen (1999) discussed above.

The explanation I offer for this result is the following. The 1950s and 1960s were a period in which the follower countries in the sample (all countries except the United States, see Figure 5) were able to use the manufacturing sector as a way of catching-up to the United States. This was possible because they had favourable conditions for entrance into the newly emerging technological system at that stage. This new technological system consisted of mass-manufacturing, based on innovations that were introduced in the United States during the first half of the $20^{\text {th }}$ century. Exogenous events such as the second world war and the period of protectionism during the Great Depression of the 1930s 'deferred' the start of this catch-up phase until the 1950s (Abramovitz and David, 1996). 

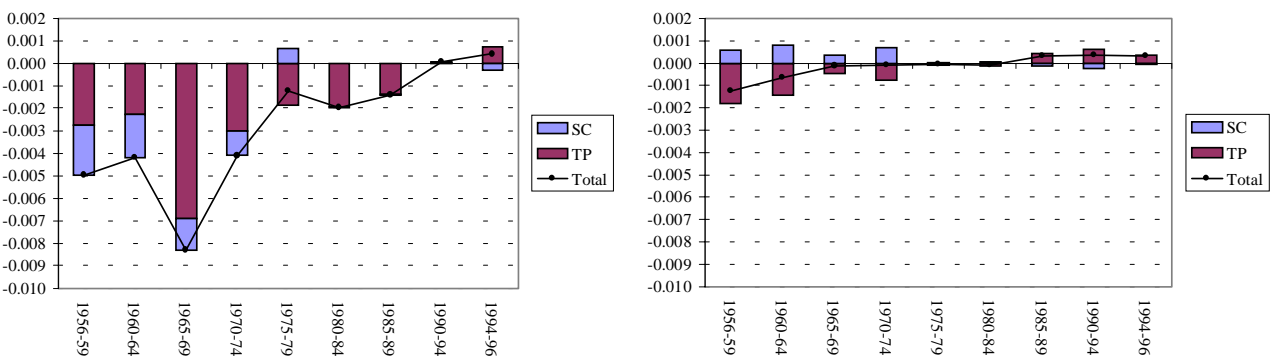

Trade
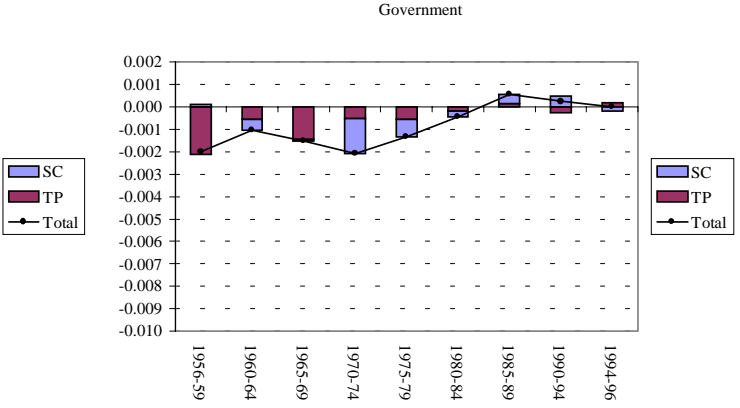

Community \& personal services
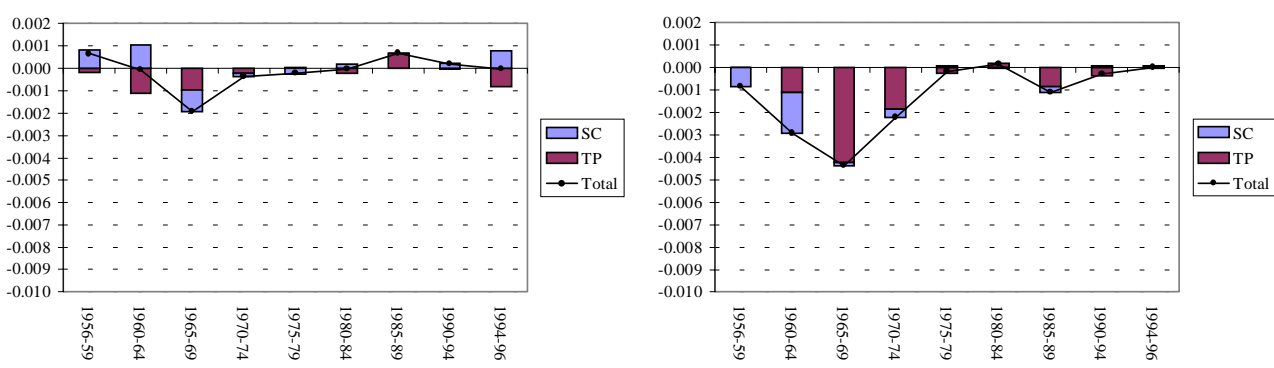

Transport \& communication
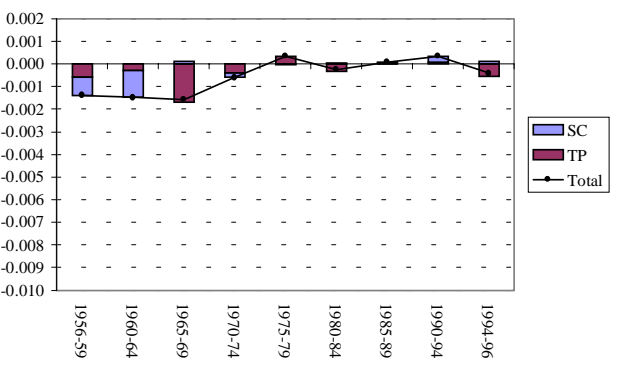

Finance, Insurance \& real estate

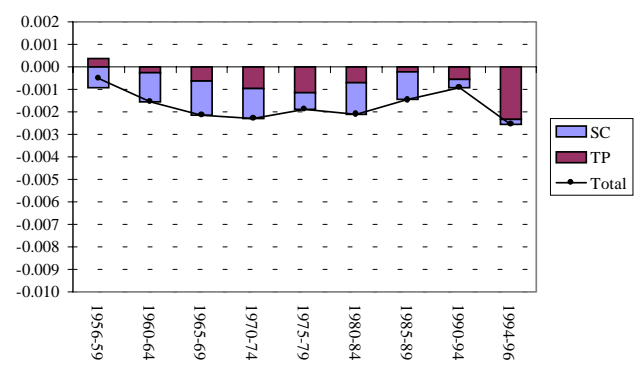

Mining
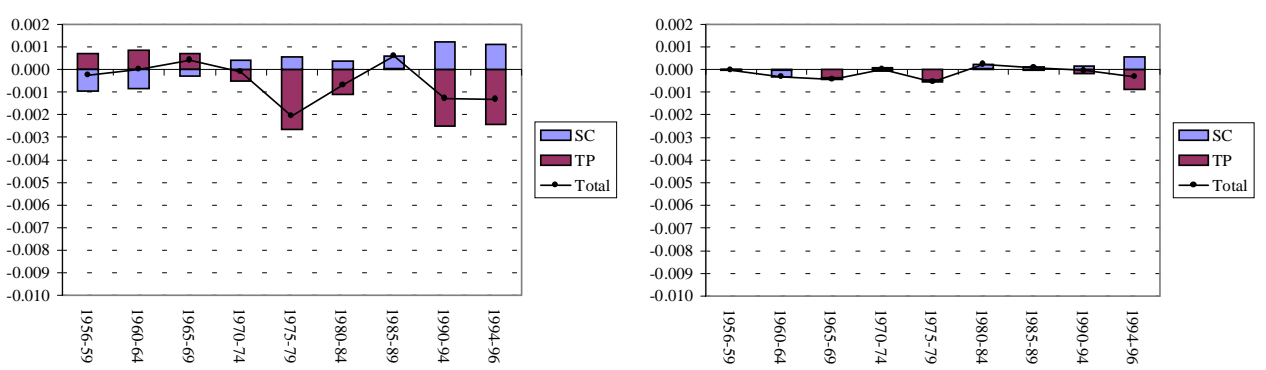

Figure 7. Contributions to convergence slowdown, sectors 
The favourable conditions that enabled the follower countries to enter the newly emerging technological system included institutional factors such as the Bretton-Woods system, the Marshall Plan, and the first phases of European economic and political integration. All of these factors contributed to strong emphasis on economies of scale through increased international trade and strong expansion of domestic demand (Nelson and Wright, 1992, Fagerberg, Guerrieri et al., 1999).

Having entered the new technological system at the crucial introduction phase (Perez and Soete, 1988), a Kaldor-Cornwall type mechanism of manufacturing driven growth set in motion rapid catching-up by these countries. However, because of the combined effect of demand saturation (Pasinetti, 1981) and the wearing-off of technological opportunities associated with the system of mass-production, the scope for catching-up began to decline after a while. This is when the strong impact of manufacturing on convergence, as well the contribution of other sectors to this process, begins to wear off in Figure 7.

A period of slow (or no) convergence arose since the early 1980s. In terms of the various contributions to convergence in Figure 7, not much happened during this period. But below the surface of the statistics, a new technological system started to emerge in the form of ICT. The mid-1990s, unfortunately the period where the data-availability stops, seem to have become the crucial phase for entry into the new technological system. If the countries in the sample are able to enter the new system as successfully as they entered during the 1950s, one might expect a new phase of catching-up in the future. What are the signs of such an event that are already visible in the graphs?

One sector that is strongly associated with the new ICT system of production is the finance, insurance, real estate and other business services sector. It is remarkable that this sector is the one in Figure 7 that shows the most steady behaviour over time. The overall contribution of this sector to convergence is not extremely high, but given the size of the sector, still significant. Importantly, structural change is a large component of this sector's contribution. Still, there is somewhat of a decline in the convergence tendency of this sector in the 1990s. The main question is what will happen to this trend. The result for the 1994-1996 period suggest that this effect is reversed, and that the sector gains a strong impulse for convergence. If this tendency sets through, the sector might become a source of renewed convergence in the ICT system.

Trade, another sector highly affected by developments in ICT shows an opposite tendency during the most recent period. The same is true for manufacturing, which is still the sector that underlies a large part of investment in ICT (hardware). Together, these three sectors may hold the key to future convergence or divergence.

\section{Conclusions ${ }^{5}$}

I have interpreted the convergence (of labour productivity) trend in a sample of the four largest EU countries, the United States and Japan over the period 1955-1996 as the result of the ability of Europe and Japan to enter in the 1950s a set of technologies developed mainly in the United States known as the 'mass-production system'. This led to a process of convergence that was mainly driven by the

\footnotetext{
${ }^{5}$ This section draws heavily on joint work with Jan Fagerberg and Paolo Guerrieri (Fagerberg, Guerrieri et al. (1999)). I alone am responsible, however, for the wording here.
} 
manufacturing sector. When technological opportunities (in manufacturing) wore off, and demand saturated, convergence slowed down, mainly since the mid-1980s.

In the mid-1990s, the world economy seems to witness the introduction phase of a new technological system, known as ICT. Although this system has a base in manufactured products (hardware), services (software as technology generating and mainly business services as technology using) plays a more important role than ever. Whether or not convergence in the sample considered will pick up again depends on whether or not the follower countries (the United States is widely seen as the leader of both the old and the new technological system) will be able to enter the new system adequately. If they are not able to do so, the window of opportunity that is now open, may close because of cumulative learning effects in the new technology (Perez and Soete, 1988).

Both national governments and the European Commission seem determined to stimulate the adoption and generation of ICT in Europe, as was, for example, shown recently at the .com summit in Lisbon. Making ICT happen requires, however, an active and broad range of policies. Education is one of them, but here the issue seems more difficult than 'to bring the internet into every classroom in Europe'. The process may also require the use of industrial policies in combination with R\&D policies, for example in order to maintain the traditional European stronghold of mobile communication. UMTS (the successor of GSM) may be a crucial initiative in this respect, and European firms should be stimulated to take and maintain the technological lead in this field. Software seems to be a field where European performance is weak, however (Dalum, Freeman et al., 1999). Strategic thinking by the EU on how to turn recent developments such as the increased use of the open source concept into a European advantage may be necessary.

The European Commission and national, regional and local governments may also play an important and active role as suppliers of digital services. In almost all fields where citizens interact with governments, one may imagine networked applications. The broad development of these will both increase the demand for technically skilled (European) firms that can implement these services, and create value-added for users. One may imagine how a virtuous circle can be set in motion by such government procurement and government supply of digital services. Finally, supporting policies in the form of, for example, enabling venture capital to be raised more easily are important.

Together, these (and possibly other, the list here is far from exhaustive) initiatives present a break with a tradition of European integration aimed at economies of scale that was initiated in the 1950s. The tearing down of trade barriers and the enlargement of the internal market has been a success story, and it has certainly added to the rapid growth and convergence that observed until the mid-1980s. However, in the new technological age, the concept of scale can no longer form the uniting principle of European policy and further integration. Economies of networks (in the broadest sense) may be a more appropriate device. 


\section{References}

Abramovitz, M. A. (1979). Rapid Growth Potential and its Realisation : The Experience of Capitalist Economies in the Postwar Period. Economic Growth and Resources, vol. 1 The major Issues, Proceedings of the fifth World Congress of the International Economic Association. E. Malinvaud. London, Macmillan: 1-51.

Abramovitz, M. A. and P. A. David (1996). Convergence and deferred catch-up: productivity leadership and the waning of American exceptionalism. The Mosaic of Economic Growth. R. Landau, T. Taylor and G. Wright. Stanford, Stanford University Press: 21-62.

Ark, B. v. (1996). Sectoral Growth Accounting and Structural Change in Post-War Europe. Quantitative Aspects of Post-War European Economic Growth. B. van Ark and N. Crafts. Cambridge, Cambridge University Press: 84-164.

Ark, B. v., E. Monnikhof and N. Mulder (1999). "Productivity in Services: An International Comparative Perspective." Canadian Journal of Economics 32: 471-499.

Baumol, W. (1967). "Macroeconomics of unbalanced growth." American Economic Review 53: 941973.

Benhabib, J. and M. M. Spiegel (1994). "The role of human capital in economic development: Evidence from aggregate cross-country data." Journal of Monetary Economics 34: 143-173.

Bernard, A. B. and C. I. Jones (1996). "Comparing Apples to Oranges: Productivity Convergence and Measurement Across Industries and Countries.” American Economic Review 86: 1216-1238.

Castells, M. (1996). The rise of the network society. Oxford, Blackwell.

Cornwall, J. (1976). "Diffusion, Convergence and Kaldor's Laws.” Economic Journal 86: 307-314.

Cornwall, J. (1977). Modern Capitalism. Its Growth and Transformation. London, Martin Robertson.

Dalum, B., C. Freeman, R. Simonetti, et al. (1999). Europe and the Information and Communications Technologies Revolution. The Economic Challenge to Europe. Adapting to Innovation Based Growth. J. Fagerberg, P. Guerrieri and B. Verspagen. Aldershot, Edward Elgar: 106-129.

Dixon, R. J. and A. P. Thirlwall (1975). "A Model of Regional Growth-Rate Differences on Kaldorian Lines." Oxford Economic Papers 11: 201-214.

Fagerberg, J. (1994). "Technology and international differences in growth rates." Journal of Economic Literature 32: 1147-1175.

Fagerberg, J. (2000). "Technological progress, structural change and productivity growth: a comparative study." Structural Change and Economic Dynamics forthcoming.

Fagerberg, J., P. Guerrieri and B. Verspagen (1999). Europe - A Long View. The Economic Challenge to Europe. Adapting to Innovation Based Growth. J. Fagerberg, P. Guerrieri and B. Verspagen. Aldershot, Edward Elgar: 1-20.

Freeman, C. (1986). Technology Policy and Economic Performance: Lessons from Japan. London, Pinter.

Freeman, C. (1994). Technological Revolutions and Catching-Up: ICT and the NICs. The Dynamics of Trade, Technology and Growth. J. Fagerberg, B. Verspagen and N. Von Tunzelmann. Aldershot, Edward Elgar: 198-221.

Freeman, C., J. Clark and L. Soete (1982). Unemployment and Technical Innovation. London, Pinter.

Freeman, C. and L. Soete (1990). "Fast Structural Change and Slow Productivity Change: Some Paradoxes in the Economics of Information Technology." Structural Change and Economic Dynamics 1: 225-242.

Freeman, C. and L. Soete (1997). The Economics of Industrial Innovation. 3rd Edition. London and Washington, Pinter. 
Gerschenkron, A. (1962). Economic Backwardness in Historical Perspective. Cambridge MA, Harvard University Press.

Gomulka, S. (1971). Inventive Activity, Diffusion and the Stages of Economic Growth. Aarhus.

Kaldor, N. (1966). Causes of the Slow Rate of Growth of the United Kingdom. Cambridge, Cambridge University Press.

Kaldor, N. (1970). "The Case for Regional Policies." Scottish Journal of Political Economy XVII: 337-348.

Kleinknecht, A. (1981). "Observations on the Schumpeterian Swarming of Innovations." Futures 13.

Kuznets, S. (1940). "Schumpeter's Business Cycles." American Economic Review 30.

Maddison, A. (1995). Monitoring the World Economy 1820-1992. Paris, OECD Development Centre.

Mensch, G. (1979). Stalemate in Technology. Innovations Overcome Depression. Cambridge, Ballinger.

Nelson, R. R. and G. Wright (1992). "The rise and fall of American technological leadership: the postwar era in an historical perspective." Journal of Economic Literature 30: 1931-1964.

Pasinetti, L. L. (1981). Structural Change and Economic Growth. A Theoretical Essay on the Dynamics of the Wealth of Nations. Cambridge, Cambridge University Press.

Perez, C. (1983). "Structural change and the assimilation of new technologies in the economic and social systems." Futures 15: 357-75.

Perez, C. and L. Soete (1988). Catching Up in Technology: Entry Barriers and Windows of Opportunity. Technical Change and Economic Theory. G. Dosi, C. Freeman, R. R. Nelson, G. Silverberg and L. Soete. London, Pinter.

Petit, P. and L. Soete (2000). Technical change and employment growth in services: analytical and policy challenges. Technology and the future of European employment. P. Petit and L. Soete. Aldershot, Edward Elgar.

Saxenian, A. (1994). Regional Advantage. Culture and Competition in Silicon Valley and Route 128. Cambridge MA and London, Harvard University Press.

Schumpeter, J. A. (1939). Business Cycles: A theoretical, historical and statistical analysis of the capitalist process. New York, McGraw-Hill.

Timmer, M. and A. E. Szirmai (2000). "Productivity Growth in Asian Manufacturing: The Structural Bonus Hypothesis Examined." Structural Change and Economic Dynamics forthcoming.

van Duijn, J. J. (1983). The Long Wave in Economic Life. London, Allen \& Unwin.

Verspagen, B. (1993). Uneven Growth Between Interdependent Economies. The Evolutionary Dynamics of Growth and Technology. Aldershot, Avebury. 